\title{
Effects of Zirconium Addition on Microstructures and Mechanical Properties of Co-29Cr-6Mo Alloy
}

\author{
Sang-Hak Lee ${ }^{1}$, Tomo Uchikanezaki ${ }^{2}$, , Naoyuki Nomura ${ }^{3}$, \\ Mitsuru Nakamura ${ }^{4}$ and Akihiko Chiba ${ }^{5}$ \\ ${ }^{1}$ Center for Regional Collaboration in Research and Education, Iwate University, Morioka 020-8551, Japan \\ ${ }^{2}$ Department of Welfare Engineering, Graduate School of Engineering, Iwate University, Morioka 020-8551, Japan \\ ${ }^{3}$ Department of Welfare Engineering, Faculty of Engineering, Iwate University, Morioka 020-8551, Japan \\ ${ }^{4}$ Department of Die-Mold and Casting Engineering, Faculty of Engineering, Iwate University, Morioka 020-8551, Japan \\ ${ }^{5}$ Institute for Material Research, Tohoku University, Sendai 980-8577, Japan
}

Co-29Cr-6Mo alloys consisting of $0 \sim 1.76 \% \mathrm{Zr}$ were prepared and heat-treated at $1210^{\circ} \mathrm{C}$ for $2 \mathrm{~h}$ or $1230^{\circ} \mathrm{C}$ for $3 \mathrm{~h}$. Three types of precipitates were identified. With more than $0.37 \% \mathrm{Zr}$ content, precipitates are mixtures of $\sigma$ phase and ( $\mathrm{Zr}$, Mo)-rich phase. The $\sigma$ phase dissolves into a matrix and the ( $\mathrm{Zr}$, Mo)-rich phases change its composition into a Zr-rich phase with heat treatment. An alloy with a solid solution containing $0.01 \% \mathrm{Zr}$ exhibits improved mechanical properties. [doi:10.2320/matertrans.48.1084]

(Received January 9, 2007; Accepted March 2, 2007; Published April 25, 2007)

Keywords: cobalt chromium molybdenum alloy, microstructure, mechanical properties, heat treatment, biomaterial, zirconium

\section{Introduction}

Co-Cr-Mo alloys are widely used as surgical implant materials due to their excellent wear resistance, corrosion resistance, and biocompatibility. ${ }^{1-3)}$ Several methods such as heat treatment, forging, and alloying are carried out to obtain reliable mechanical properties of $\mathrm{Co}-\mathrm{Cr}-\mathrm{Mo}$ alloys. ${ }^{4-6)} \mathrm{Be}-$ sides, it is not only the major solute elements like $\mathrm{Cr}$ and $\mathrm{Mo}$ which influence mechanical properties and other functional properties required for implant materials, but also minor solutes. Carbon is a representative minor element facilitating the formation of $\mathrm{M}_{23} \mathrm{C}_{6}$ carbides and stabilizing an fcc $\mathrm{Co}$ matrix of cast $\mathrm{Co}-\mathrm{Cr}-\mathrm{Mo}$ alloy. ${ }^{7)} \mathrm{Ni}, \mathrm{Fe}$, and $\mathrm{Zr}$ also stabilize an fcc structure of Co. ${ }^{8)}$ In addition, Kurosu et al. has reported that a $0.05 \%$ (all in mass \%) $\mathrm{Zr}$ addition to $\mathrm{Co}-\mathrm{Cr}-\mathrm{Mo}$ alloys efficiently suppresses the release of $\mathrm{Ni}$ ions, which causes adverse biological effects. ${ }^{9)} \mathrm{Zr}$ is known to exhibit no toxic or carcinogenic reactions to body tissue or cells. ${ }^{10)}$ Garza et al. reported that a $0.017 \% \mathrm{Zr}$ addition greatly improves the mechanical properties of cast $\mathrm{Co}-\mathrm{Cr}-\mathrm{Mo}-\mathrm{C}$ alloys. ${ }^{11)}$ In this study, we investigated the effect of $\mathrm{Zr}$ addition on $\mathrm{Ni}$-, C-free Co-29Cr-6Mo alloys for the possibility of new hot-forged alloys. Pre-heat treated microstructure and mechanical properties before the hot-forging process are investigated to understand the change of microstructures and mechanical properties of $\mathrm{Zr}$ added $\mathrm{Co}-\mathrm{Cr}-\mathrm{Mo}$ alloys.

\section{Experimental Procedure}

Co-Cr-Mo-Zr alloys were prepared by using a vacuum induction melting furnace and a metallic mold. The analyzed chemical composition of the alloy obtained is shown in Table 1. Some amount of added $\mathrm{Zr}$ reacted with oxygen or trace elements in raw materials during the melting and casting process. Therefore, chemically analyzed $\mathrm{Zr}$ contents

*Graduate Student, Iwate University
Table 1 Chemical composition of the experimental alloys (mass\%).

\begin{tabular}{lccccccc}
\hline Alloy & $\mathrm{Cr}$ & $\mathrm{Mo}$ & $\mathrm{C}$ & $\mathrm{Si}$ & $\mathrm{Ni}$ & $\mathrm{Zr}$ & $\mathrm{Co}$ \\
\hline $0 \mathrm{Zr}$ & 28.80 & 5.61 & $<0.01$ & 0.08 & 0.17 & - & Bal. \\
$0.1 \mathrm{Zr}$ & 28.72 & 5.67 & $<0.01$ & 0.08 & 0.17 & 0.01 & Bal. \\
$0.5 \mathrm{Zr}$ & 28.72 & 5.68 & $<0.01$ & 0.07 & 0.17 & 0.37 & Bal. \\
$1 \mathrm{Zr}$ & 28.77 & 5.62 & $<0.01$ & 0.07 & 0.17 & 0.82 & Bal. \\
$2 \mathrm{Zr}$ & 28.70 & 5.76 & $<0.01$ & 0.08 & 0.16 & 1.76 & Bal. \\
\hline
\end{tabular}

are smaller than the nominal composition of $\mathrm{Zr}$ contents. However, the experimental alloys are referred to as $0 \mathrm{Zr}$, $0.1 \mathrm{Zr}, 0.5 \mathrm{Zr}, 1 \mathrm{Zr}$, and $2 \mathrm{Zr}$ alloy according to their nominal $\mathrm{Zr}$ composition in this study. Experimental alloys were heattreated at $1210^{\circ} \mathrm{C}$ for $2 \mathrm{~h}$ or at $1230^{\circ} \mathrm{C}$ for $3 \mathrm{~h}$ in a tube chamber furnace using a halogen lamp heating system under an atmosphere of high purity Ar gas. Alloys were waterquenched immediately after heat treatment to examine their high temperature structure. The microstructures of as-cast and heat-treated specimens were determined by means of an optical microscope (OM), and an electron probe micro analyzer (EPMA) equipped with wave-length dispersive Xray spectroscopy (WDS). The area fraction of the second phase was analyzed by using an image analysis program. Xray diffraction patterns were measured between $2 \theta=40^{\circ}$ and $80^{\circ}$ using $\mathrm{Cu} \mathrm{K} \alpha$ radiation. Tensile tests were performed at an initial strain rate of $5.2 \times 10^{-4} \mathrm{~s}^{-1}$ using an Instron-type testing machine. At least three specimens were tested and the results were summarized as a mean value. The gauge size of the tensile specimens was $16 \mathrm{~mm}$ in length, $3 \mathrm{~mm}$ in width and $1.3 \mathrm{~mm}$ in thickness. Rockwell $\mathrm{C}$ scale hardness measurements were made on polished surfaces of as-cast and heat-treated specimens.

\section{Results and Discussion}

Figures 1(a) and 1(c) show optical micrographs of as-cast $0 \mathrm{Zr}$ and $1 \mathrm{Zr}$ alloys, respectively. The microstructure of as- 

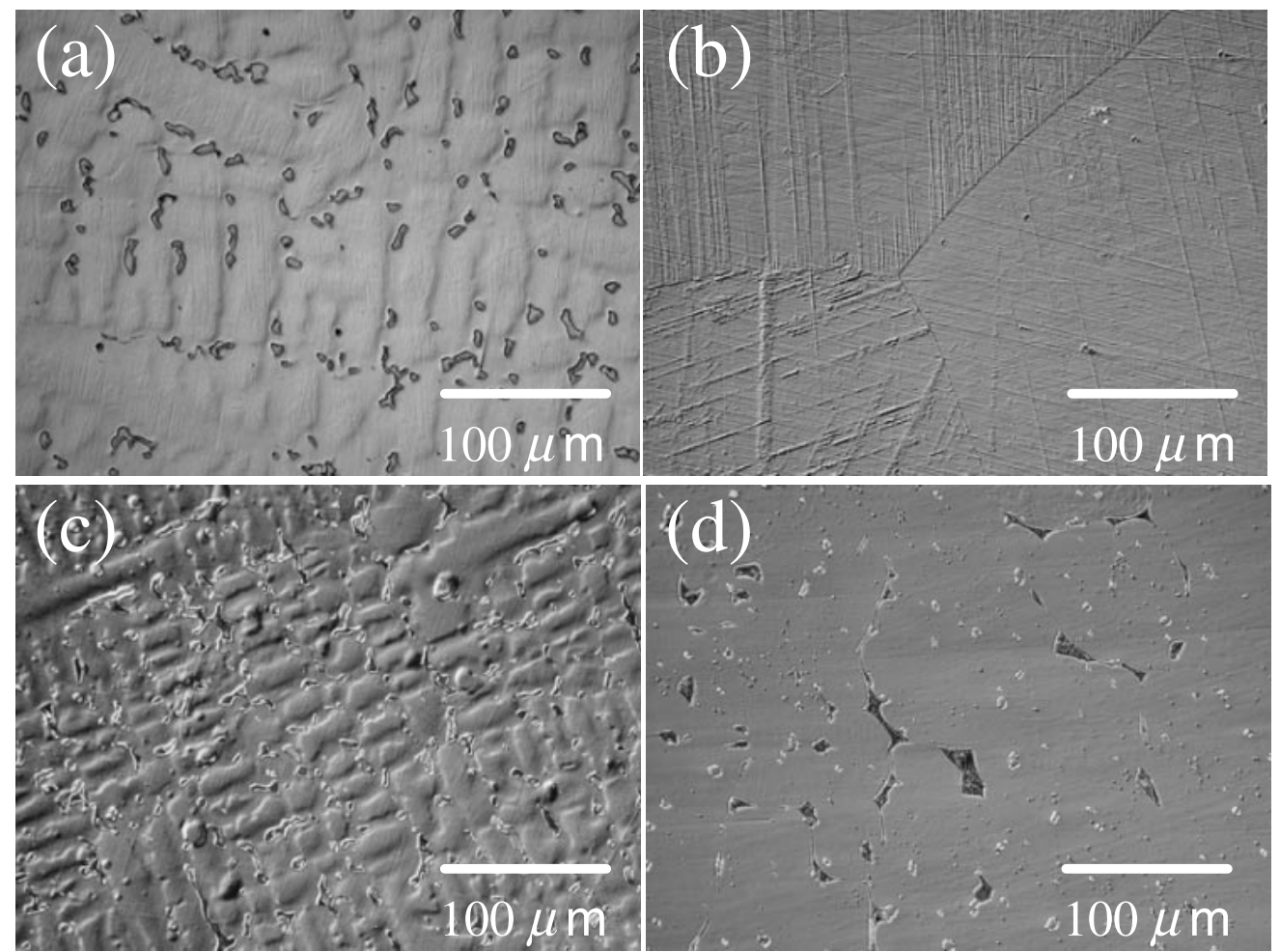

Fig. 1 Microstructures of Co-Cr-Mo alloys with a different $\mathrm{Zr}$ content. Co-29Cr-6Mo-0Zr (a) as-cast, (b) $1230^{\circ} \mathrm{C}, 3 \mathrm{~h} \mathrm{Co-29Cr-6 \textrm {Mo } -}$ $0.82 \mathrm{Zr}$ (c) as-cast, (d) $1230^{\circ} \mathrm{C}, 3 \mathrm{~h}$.

cast $0 \mathrm{Zr}$ and $1 \mathrm{Zr}$ specimens shows a cored matrix with interdendritic precipitates. By increasing the amount of $\mathrm{Zr}$ added, a dense precipitation of the second phase is observed in the interdendritic region. However, there is no obvious change in the morphology of the second phase and casting structure of the alloys with the addition of $\mathrm{Zr}$. Optical microstructures of heat-treated alloys at $1230^{\circ} \mathrm{C}$ for $3 \mathrm{~h}$ are also shown in Figs. 1(b) and 1(d). It is found that dendritic structure disappears and significant grain growth occurs in the heat-treated specimens. However, the heat-treated specimens with $\mathrm{Zr}$ content higher than $0.37 \%$ show reduced second phase in comparison with as-cast specimens, and the second phase does not achieve complete dissolution even after heat treatment at $1230^{\circ} \mathrm{C}$ for $3 \mathrm{~h}$. In particular, a nonnegligible amount of second phase remained along the grain boundaries and intergranular regions of $1 \mathrm{Zr}$ and $2 \mathrm{Zr}$ alloys after the heat treatment. The solubility limit of $\mathrm{Zr}$ in Co$29 \mathrm{Cr}-6 \mathrm{Mo}$ alloys is responsible for the remnant of second phase. According to a ternary phase diagram of $\mathrm{Co}-\mathrm{Cr}-\mathrm{Zr}$ alloy, the solubility of $\mathrm{Zr}$ is very limited (at most $1 \%$ ). ${ }^{12}$ ) Therefore, the solubility limit of $\mathrm{Zr}$ in $\mathrm{Co}-29 \mathrm{Cr}-6 \mathrm{Mo}$ alloy is much smaller than $1 \%$. The area fraction of a whole second phase is illustrated as a function of $\mathrm{Zr}$ content and heat treatment condition in Fig. 2. $0 \mathrm{Zr}$ and $0.1 \mathrm{Zr}$ alloys show almost the same area fraction of second phase with each other. With a $\mathrm{Zr}$ content greater than $0.37 \%$, the area fraction of second phase increases with $\mathrm{Zr}$ content. Figures 3(a) to (d) shows backscattered electron images and line analyses of $0.1 \mathrm{Zr}$ alloys. The second phase precipitating at the interdendritic region of as-cast alloy shows higher $\mathrm{Cr}$ and Mo content (Figs. 3(a) and (b)). It is well known that the solute elements $\mathrm{Cr}$ and Mo constitute an $\sigma$ phase (topological close packing

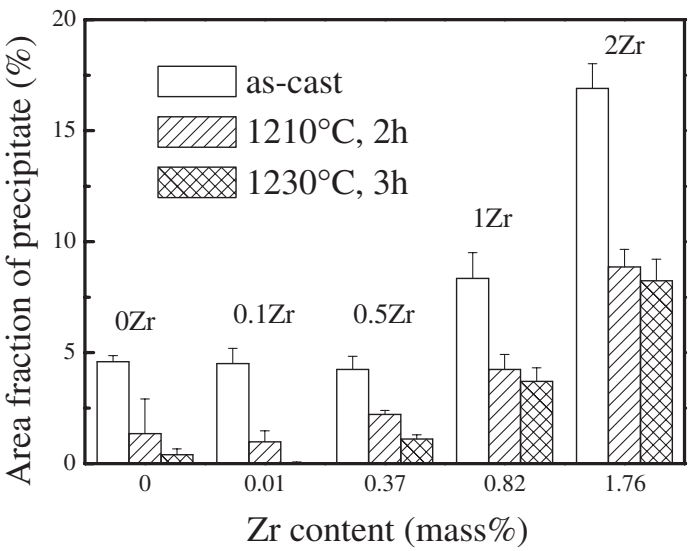

Fig. 2 Area fraction of precipitates in Co-29Cr-6Mo alloys as a function of $\mathrm{Zr}$ content and heat treatment condition.

phase) which exists in the interdendritic region and grain boundaries of as-cast Co-based alloys. ${ }^{13)}$ From the above observations, it is confirmed that the second phase of as-cast $0.1 \mathrm{Zr}$ alloy is $\sigma$ phase. In the case of $0.1 \mathrm{Zr}$ alloy heat-treated at $1230^{\circ} \mathrm{C}$ for $3 \mathrm{~h}$ (Figs. 3(c) and (d)), the alloy shows an almost homogeneous structure with a very small amount of $\sigma$ phase. Figure 4 shows backscattered electron images and line analyses of $0.5 \mathrm{Zr}$ alloys. From the profile of line analyses, it is found that the composition of second phase of the as-cast $0.5 \mathrm{Zr}$ alloy (Figs. 4(a) and (b)) is different from that of the ascast $0.1 \mathrm{Zr}$ alloy. The peripheral regions of the precipitates, colored in light grey, are separated from the interior region colored in dark grey. It is found that $\mathrm{Zr}$ and $\mathrm{Mo}$ are concentrated in the peripheral region, whereas $\mathrm{Mo}$ and $\mathrm{Cr}$ are 

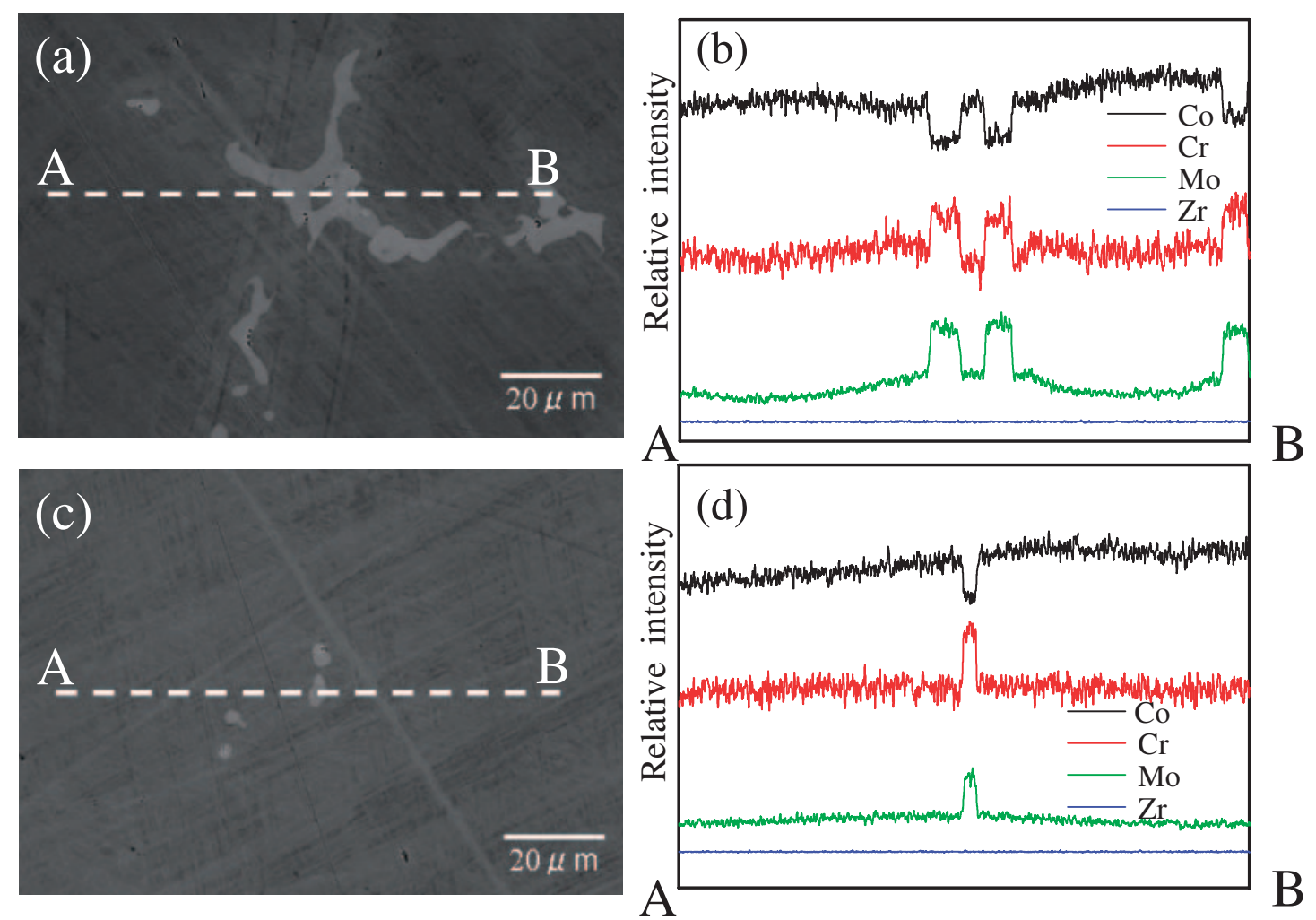

Fig. 3 EPMA-BEI micrographs and line analyses of Co-29Cr-6Mo-0.01Zr alloys. (a), (b) as-cast (c), (d) $1230^{\circ} \mathrm{C}, 3 \mathrm{~h}$.
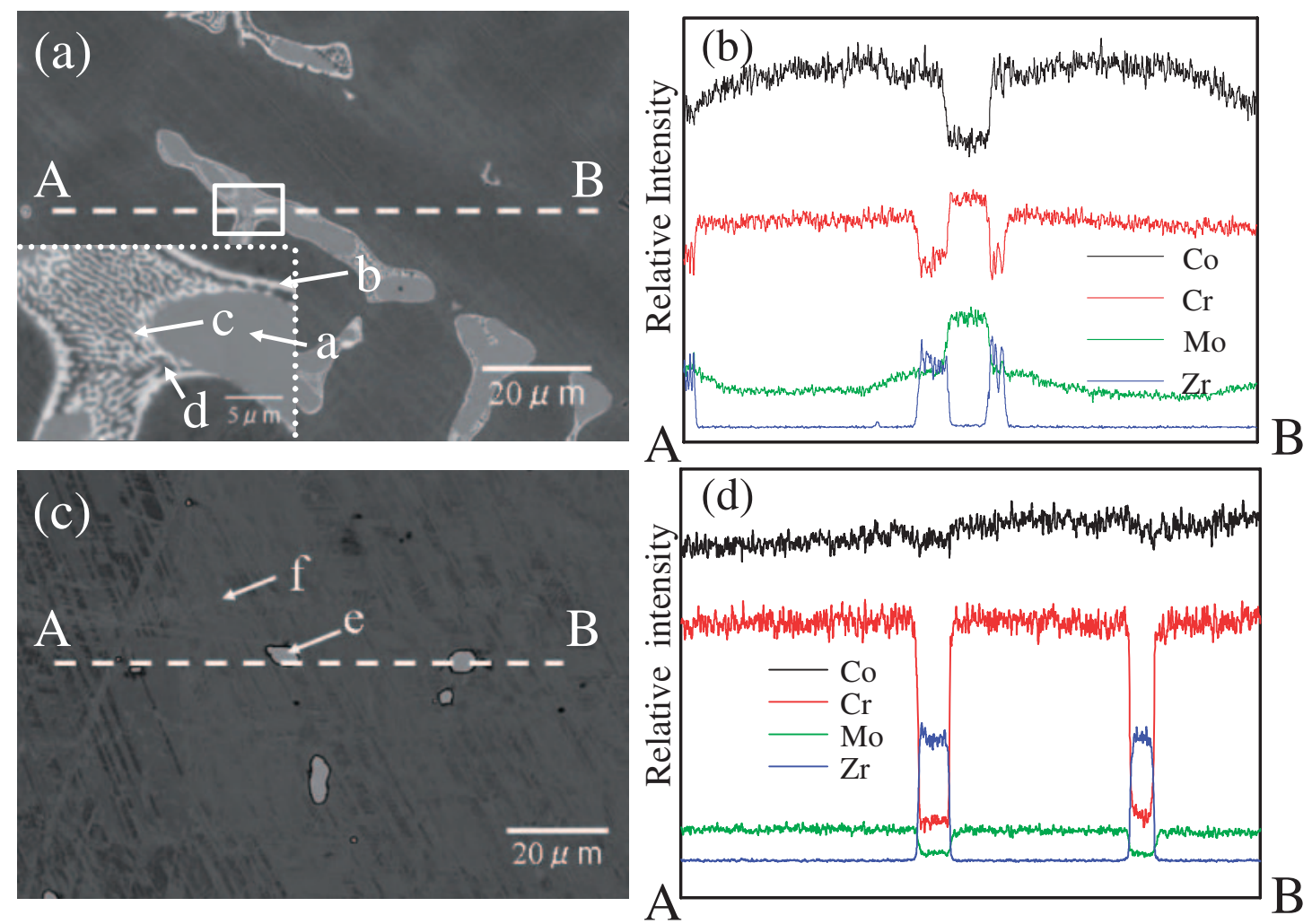

Fig. 4 EPMA-BEI micrographs and line analyses of Co-29Cr-6Mo-0.37Zr alloys. (a), (b) as-cast (c), (d) $1230^{\circ} \mathrm{C}, 3 \mathrm{~h}$.

concentrated in the interior region compared with the concentration of those elements in the matrix. These observations indicate that the interior region and the peripheral region are $\sigma$ phase and $(\mathrm{Zr}$, Mo)-rich phase, respectively. The inset micrograph of Fig. 4(a), i.e. the magnified image indicated by a square, shows a lamella structure. Table 2 shows the results of the quantitative analysis from the inset figure of Fig. 4(a) and from Fig. 4(c). 
Table 2 EPMA quantitative analysis result of Co-29Cr-6Mo-Zr alloys scanned from regions shown in Fig. 4 (mass\%).

\begin{tabular}{cccccc}
\hline Region & Phases & Co & Cr & Mo & \multicolumn{1}{c}{$\mathrm{Zr}$} \\
\hline a & $\begin{array}{c}\sigma \text { phase } \\
\text { b }\end{array}$ & 49.12 & 33.81 & 17.05 & 0.02 \\
& $\begin{array}{c}\text { Light grey phase } \\
\text { (outer) }\end{array}$ & 54.64 & 9.75 & 11.27 & 24.34 \\
c & Light grey phase & 56.61 & 9.95 & 10.27 & 23.17 \\
d & (inner) & & & & \\
e & Dark grey phase & 65.30 & 25.28 & 8.70 & 0.72 \\
f & Zr-rich phase & 59.77 & 9.37 & 1.25 & 29.61 \\
\hline
\end{tabular}

The quantitative results show the lamella structure consisting of $(\mathrm{Zr}, \mathrm{Mo})$-rich phase (pointed by arrows $\mathrm{b}$ and c, light grey phase) and slightly Co-rich phase (pointed by arrow d, dark grey phase). The outer and inner side of ( $\mathrm{Zr}, \mathrm{Mo})$-rich phase show no difference in chemical composition. It is found from the table that the composition of Co-rich phase is almost the same as that of the matrix, although the $\mathrm{Cr}$ content is slightly lower in the Co-rich phase than in the matrix. Thus it is inferred that the lamella structure is formed by a eutectic reaction between the Co matrix phase, i.e. $\gamma$ phase, and the (Zr, Mo)-rich phase during solidification. Therefore, this lamella formation can be described as following: During solidification, since the solubility of $\mathrm{Zr}$ and $\mathrm{Mo}$ is more limited in the Co-based alloy than that of $\mathrm{Cr}$, the off-eutectic composition solidifies first forming dendrite, and the $(\mathrm{Zr}$, Mo)-rich phase is formed along the interdendritic region in the remaining liquid. Then, the quasi-eutectic composition of (Zr, Mo)-rich phase and Co matrix phase constitute the lamella structure. At the same time, the $\sigma$ phase precipitating adjacent to the ( $\mathrm{Zr}, \mathrm{Mo}$ )-rich phase would grow into a major second phase.

The resultant structure of $0.5 \mathrm{Zr}$ alloy heat-treated at $1230^{\circ} \mathrm{C}$ for $3 \mathrm{~h}$ mainly consists of an almost homogeneous matrix and second phase particles (Figs. 4(c) and (d)). The line analysis of the second phase (d) shows that although a slight decrease in Mo content and a significant decrease in $\mathrm{Cr}$ content are identified in the second phase particles, the $\mathrm{Zr}$ content exhibits a drastic increase. This indicates that heat treatment changes the composition of the ( $\mathrm{Zr}, \mathrm{Mo})$-rich phase observed in as-cast $0.5 \mathrm{Zr}$ alloy into $\mathrm{Zr}$-rich phase. According to quantitative analyses in Table 2 , the $\mathrm{Zr}$ content of $0.12 \%$ is detected from the Co matrix, indicating that approximately $0.12 \% \mathrm{Zr}$ can be soluble in the Co-29Cr-6Mo alloy. This is coincidence with the result of area fraction of second phase in Fig. 2 that the second phase increases when the $\mathrm{Zr}$ content is greater than $0.37 \%$. The Mo content of the $\mathrm{Zr}$-rich phase is smaller than that of the Co matrix. The $\mathrm{Cr}$ content of the $\mathrm{Zr}$ rich phase is the lowest level among the formed phases.

The effect of $\mathrm{Zr}$ content and heat treatment conditions on the tensile strength is illustrated in Fig. 5. 0.1Zr alloys show higher tensile strength in the as-cast and the heat-treated conditions than other alloys. Tensile strength decreases with increasing $\mathrm{Zr}$ content from $0.01 \%$. As described above, $\mathrm{Zr}$ content greater than $0.37 \%$ caused second-phase precipitation in the intergranular region. Chiba et al. reported that a small addition of $\mathrm{Zr}$ greatly increases tensile strength and

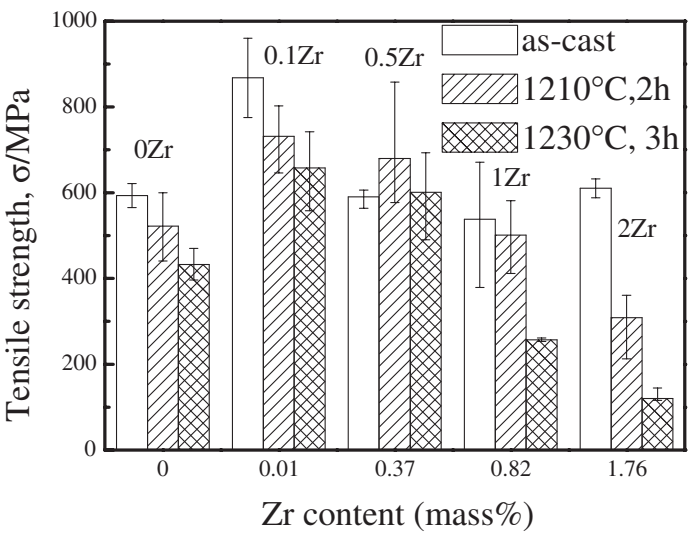

Fig. 5 Effect of $\mathrm{Zr}$ content and heat treatment condition on the tensile strength of Co-29Cr-6Mo alloys.

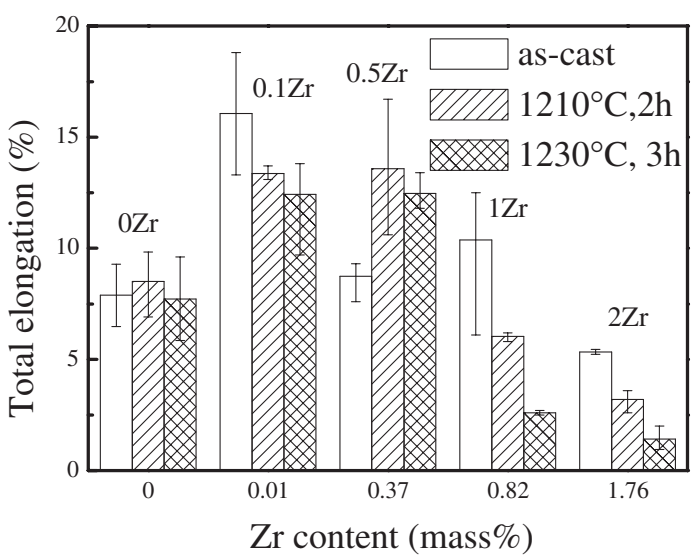

Fig. 6 Effect of $\mathrm{Zr}$ content and heat treatment condition on the total elongation of Co-29Cr-6Mo alloys.

elongation in superalloy. ${ }^{14)}$ A small addition of $\mathrm{Zr}$ effectively suppresses the segregation of harmful impurity at grain boundaries. It can be thought that $\mathrm{Zr}$ has a similar effect on the Co-based alloys. This is why the yield of $\mathrm{Zr}$ amount is much smaller than the addition in this study. However, a small content $(0.01 \%)$ of $\mathrm{Zr}$ react with any trace elements could not be detected by EPMA-WDS analysis, and $0.01 \% \mathrm{Zr}$ added alloy has no distinctive structural features compared to other $\mathrm{Zr}$ added alloys except for smaller amount of second phase. Moreover, tensile strength decreases with increasing heat-treatment temperature. Increasing the heat-treatment temperature is responsible for grain growth. Although heat treatments eliminate a certain amount of intergranular second phase, larger grain size and residual intergranular second phase decrease tensile strength. The dependence of total elongation on $\mathrm{Zr}$ content shows a similar tendency to that of tensile strength (Fig. 6). On the contrary, hardness increases with increasing $\mathrm{Zr}$ content (Fig. 7). This is due to the fact that the increased second phase contributes to improvement in hardness. Both the second phase and grain size play an important role in determining the mechanical properties of the alloys. It is generally known that the precipitation of $\sigma$ phase can cause embrittlement in Co-based alloys. ${ }^{15)}$ It is apparent from Figs. 6 and 7 that elongation was drastically reduced and hardness increased with increasing $\mathrm{Zr}$ content. 


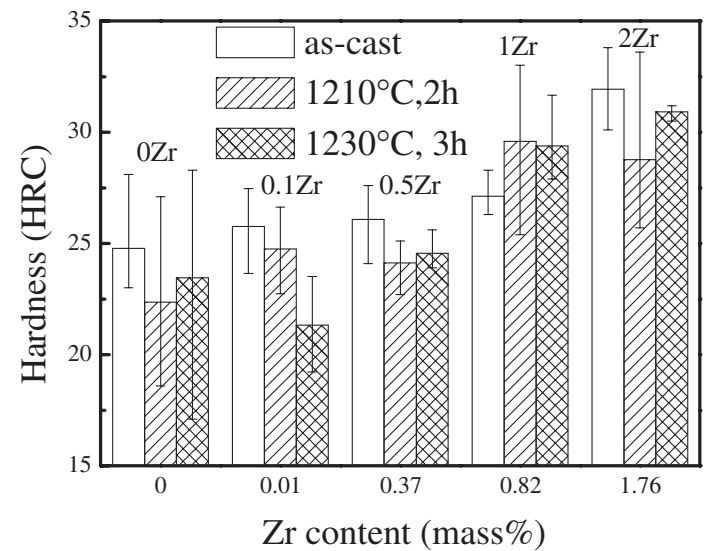

Fig. 7 Effect of $\mathrm{Zr}$ content and heat treatment condition on the hardness of Co-29Cr-6Mo alloys.

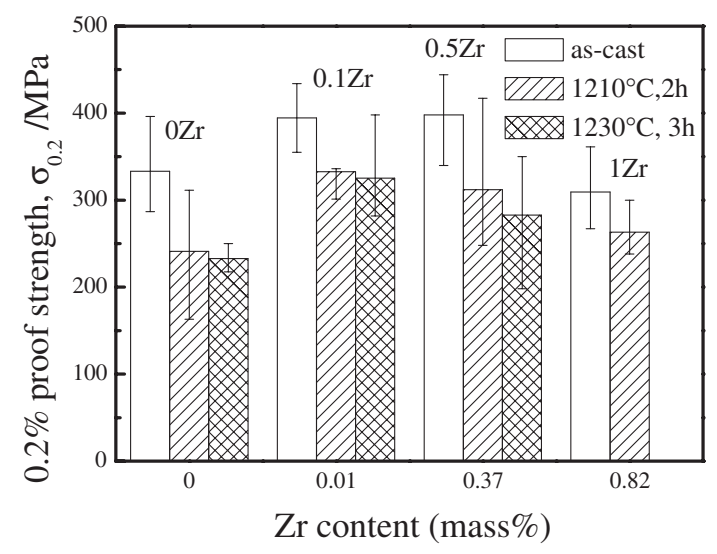

Fig. 8 Effect of $\mathrm{Zr}$ content and heat treatment condition on the $0.2 \%$ proof strength of Co-29Cr-6Mo alloys.

This means that the second phases associate with $\mathrm{Zr}$ are also brittle in the same manner as an $\sigma$ phase. These brittle second phases in as-cast alloys and the Zr-rich phase in heat-treated alloys have a detrimental effect on the mechanical properties of these alloys. The $0.2 \%$ proof strength slightly decreases with $\mathrm{Zr}$ content after reaching a maximum value at $0.01 \% \mathrm{Zr}$ content (Fig. 8). However, the $1 \mathrm{Zr}$ alloy heat-treated at $1230^{\circ} \mathrm{C}$ for $3 \mathrm{~h}$ and $2 \mathrm{Zr}$ alloys are so brittle that they show immature fracture behavior.

\section{Conclusion}

Microstructure and mechanical properties of $\mathrm{Zr}$ added Co-
29Cr-6Mo biomedical implant alloys are investigated and the following results are obtained:

(1) The soluble limit of $\mathrm{Zr}$ in $\mathrm{Co}-29 \mathrm{Cr}-6 \mathrm{Mo}$ is approximately $0.12 \%$ by water-cooling from $1230^{\circ} \mathrm{C}$ to room temperature. The over-added $\mathrm{Zr}$ formed a second phase such as ( $\mathrm{Zr}, \mathrm{Mo})$-rich phase under an as-cast condition and $\mathrm{Zr}$-rich phase under a heat-treated condition.

(2) The tensile strength and the elongation increase with $\mathrm{Zr}$ content, showing maximum value at $0.01 \% \mathrm{Zr}$. The tensile strength and the elongation of the $0.01 \% \mathrm{Zr}$ alloy are respectively $31.6 \%$ and $51 \%$ higher than those of the $0 \% \mathrm{Zr}$ alloy under an as-cast condition.

(3) The over-added $\mathrm{Zr}$ content (more than $0.37 \%$ ) exhibits a detrimental effect on the mechanical properties of the abovementioned alloys, except for hardness.

\section{Acknowledgement}

Authors would like to thank Ph. D. Toshinori Kowata of Iwate University for the technical support. This research was supported by a Cooperation of Innovative Technology and Advanced Research in Evolutional Area from the Ministry of Education, Science and Culture of Japan.

\section{REFERENCES}

1) P. Huang, A. Salinas-Rodriguez and H. F. López: Mater. Sci. Technol. 15 (1999) 1324-1330.

2) L. C. Lucas, R. A. Buchanan, J. E. Lemons and C. D. Griffin: J. Biomed. Res. 16 (2004) 799-810.

3) D. Granchi, G. Ciapetti, S. Stea, L. Savarino, F. Filippini, A. Sudanese, G. Zinghi and L. Montanaro: Biomater. 20 (1999) 1079-1086.

4) L. Z. Zhuang and E. W. Langer: J. Mater. Sci. 24 (1989) 381-388.

5) R. N. J. Taylor and R. B. Waterhouse: J. Mater. Sci. 18 (1983) $3265-$ 3280 .

6) A. Chiba, K. Kumagai, H. Takeda and N. Nomura: Mater. Sci. Forum 475-479 (2005) 2317-2322.

7) S. H. Lee, E. Takahashi, N. Nomura and A. Chiba: Mater. Trans. 47 (2006) 287-290.

8) T. Ericsson: Acta Metall. 14 (1966) 853-865.

9) S. Kurosu, N. Nomura, K. Yamaguchi, S. Fujinuma and A. Chiba: J. Japan Inst. Metals 69 (2005) 886-891.

10) Y. H. Yun, V. T. Turitto, K. P. Daigle, J. A. Davidson and S. M. Slack: J. Biodmed. Mater. Res. 32 (1996) 77-85.

11) Z. de la Garza, M. Herrera-Trejo, M. R. Castro, E. N. Ramírez and J. N. Méndez: J. Mater. Eng. Per. 10 (2001) 153-156.

12) T. Chart, A. Dinsdale and F. Putland: The NPL Alloydata Bank, (National Physical Laboratory, U.K., Symposium, 34, 1980) pp. 235244.

13) H. Mohammed and K. Asgar: J. Dent. Res. 53 (1974) 7-14.

14) A. Chiba, S. Hanada and S. Watanabe: Mater. Trans., JIM 35 (1994) 286-290.

15) D. L. Klarstrom: J. Mater. Eng. Per. 2 (1993) 523-530. 